\title{
Band structures and nitrogen doping effects in zinc titanate photocatalysts
}

José C. Conesa

Instituto de Catálisis y Petroleoquímica, CSIC

Campus de Excelencia UAM-CSIC

Marie Curie 2, L10, Cantoblanco

28049 Madrid, Spain

Tel. +34-915854766, fax +34-915854760, e-mail jcconesa@icp.csic.es

\begin{abstract}
The electronic structure of $\mathrm{ZnTiO}_{3}, \mathrm{Zn}_{2} \mathrm{TiO}_{4}$ and $\mathrm{Zn}_{2} \mathrm{Ti}_{3} \mathrm{O}_{8}$ is investigated using a hybrid DFT method in which the exchange mixing coefficient is obtained through its relation with the dielectric constant (also computed at the hybrid DFT level). Bandgaps higher than those of the simple oxides are predicted, in agreement with some experimental data; but in the case of spinel structures bandgaps also appear to depend significantly on the (dis)ordering of the cations at octahedral sites, implying a strong influence of the preparation details on the final gap values. The change in the electronic structure of the spinel titanates which occurs when they are nitrided can lead to photocatalytic activity with visible light, as is known to happen with $\mathrm{TiO}_{2}$ and other oxides; but here the cation vacancy suppression effect which accompanies the transformation makes the nitridation process much more favourable, as shown by total energy DFT calculations. These zinc titanate spinels are thus promising candidates to achieve via nitridation efficient and robust photocatalysts active with visible light. All these compounds show a lower conduction band edge constituted mainly by Ti-centred orbitals; this may have influence on the details of the photocatalytic reaction mechanisms.
\end{abstract}

Keywords: Zinc titanate; photocatalyst; nitrogen doping; stability; hybrid DFT; bandgap 


\section{Introduction}

The best known and most used photocatalyst is titanium dioxide, especially in its anatase form that is considered to be the most photoactive one [1, 2]. Its advantages lie in its relatively low cost, good chemical stability, low toxicity and high efficiency in separating photogenerated charges and transferring them to other substances at its interface. Zinc oxide, normally in the wurtzite structure, is another photocatalytically active simple material [3] which, although less frequently used than anatase due to its lower stability, shares most of the other advantages. Both oxides share one main disadvantage: a relatively large bandgap width (in both oxides it is around $3.2 \mathrm{eV}$ at ambient temperature), which causes that only ultraviolet light can be absorbed and used to drive chemical changes, preventing the use of these oxides for an efficient harvesting of solar energy.

Still, the properties of these two oxides have led a number of authors to examine photocatalysts which combine them, either in form of biphasic composites or as singlephase mixed oxides. In the first case a number of studies report improvements in the photocatalytic activity $[4,5,6]$ which are usually ascribed to a better electron-hole separation at the interface between both oxides in a similar way as proposed for the anatase-rutile interface [7], although some authors state that the bands of $\mathrm{ZnO}$ lie at higher levels than those of anatase $[4,8]$ while others claim the contrary to be true $[5$, 9]; recent work by this author based on hybrid DFT calculations [10] indicates that the second interpretation is the correct one. In the case of the mixed oxides photocatalytic activity has been found as well [11, 12, 13], although it is not clear whether improvement over the individual simple oxides is obtained; on the other hand some authors claim that the bandgaps of these photocatalysts are close to those of $\mathrm{ZnO}$ or $\mathrm{TiO}_{2}$ [12] while others report that the bandgap is pushed to higher values [11, 14]. Of particular interest is that these mixed oxides seem able to admit significant levels of nitrogen doping, an alteration that brings the range of active wavelengths into the visible region of the spectrum leading to interesting photocatalytic properties [15]; in these works it is worth noting that relatively high amounts of $\mathrm{N}$ atoms could be inserted in these systems (up to ca. 1/8 of the anions), and that the thermal nitriding treatment seems to favour the crystallization of the cubic spinel structure. This further justifies the interest of studying and understanding the properties of these compounds.

Two crystal structure types are known for mixed titanium-zinc oxides (normally described as zinc titanates). The first one is rhombohedral (trigonal) $\mathrm{ZnTiO}_{3}$, with an ilmenite-type structure [16] which is derived from that of corundum by ordering both cations in alternating layers perpendicular to the trigonal symmetry axis (Fig. 1a); in this structure both cations have a more or less distorted octahedral coordination.

Other zinc titanates are known which have spinel-type structure. The best known one is $\mathrm{Zn}_{2} \mathrm{TiO}_{4}$, an inverse spinel in which the $\mathrm{Zn}$ and $\mathrm{Ti}$ cations that populate in 1:1 ratio the octahedral sites have, in the most stable state of the compound, a specific ordering which leads to a supercell with the primitive tetragonal space group $P 4_{1} 22$ [17] and in which the unit cell contents has the formula $\mathrm{Zn}_{8} \mathrm{Ti}_{4} \mathrm{O}_{16}$ (Fig. 1b), i.e. it is twice as large as in the primitive cell of the parent spinel lattice. It should be noted here that a recent study of a $\mathrm{Zn}_{2} \mathrm{TiO}_{4}$ single crystal [18] reports a rather high bandgap value $\left(\mathrm{E}_{\mathrm{g}}=5.05 \mathrm{eV}\right)$. Another known zinc titanate with spinel-type structure is $\mathrm{Zn}_{2} \mathrm{Ti}_{3} \mathrm{O}_{8}$. In this case all $\mathrm{Zn}$ ions have tetrahedral coordination (the preferred one for $\mathrm{Zn}$ in most oxides) and all $\mathrm{Ti}$ ions occupy octahedrally coordinated sites but do not populate all of them: $25 \%$ of the octahedral sites are empty, and in the most stable configuration of this oxide these 
cation vacancies are ordered in a specific way [19] leading to a cubic primitive lattice with space group $\mathrm{P}_{3} 32$ and volume four times larger than the primitive cell of the spinel lattice, i.e. with a total contents of $\mathrm{Zn}_{8} \mathrm{Ti}_{12} \mathrm{O}_{32}$ in the crystal cell (Fig. 1c).

Both $\mathrm{Zn}_{2} \mathrm{TiO}_{4}$ and $\mathrm{Zn}_{2} \mathrm{Ti}_{3} \mathrm{O}_{8}$ are obtained frequently with full cation disorder in the octahedral sites, so that their diffractograms display only features typical of the parent fcc spinel structure. It is not surprising therefore that spinel-type zinc titanate materials with $\mathrm{Zn}: \mathrm{Ti}$ atomic ratios intermediate between the mentioned 2:1 and 2:3 values can be prepared in which the octahedral positions contain $\mathrm{Ti}, \mathrm{Zn}$ and vacant sites in a disordered manner; indeed "cubic $\mathrm{ZnTiO}_{3}$ " has been reported more than once in the literature [11b,12b,20], but it is metastable and transforms to the trigonal form at high temperature [12a]. Of these spinel-type structures the $\mathrm{Zn}_{2} \mathrm{TiO}_{4}$ inverse one seems to be most stable, and indeed $\mathrm{Zn}_{2} \mathrm{Ti}_{3} \mathrm{O}_{8}$ decomposes upon annealing at high temperature giving $\mathrm{Zn}_{2} \mathrm{TiO}_{4}$, rutile-type $\mathrm{TiO}_{2}$ and other phases [21]. This might be related to the fact that zinc titanate spinels with lower $\mathrm{Zn}$ :Ti ratios have necessarily cation vacancies, which implies less compact structures and smaller Madelung energies (or, from a more chemical point of view, a smaller number of cation-anion bonds) so that their cohesive energy will be lower. It may be mentioned finally that some of these titanates have found practical use as ceramic components for microwave applications [22] or as sulphur absorbents in chemical plants [23].

These mixed oxides have only scarcely been studied with quantum methods. To this author's knowledge, there is one modelling of $\mathrm{Zn}_{2} \mathrm{TiO}_{4}$ [24], carried out at the standard GGA level, which was concerned only with energetics and order/disorder aspects of the structure, without any consideration for the bandgap; another publication exists (in Chinese), using also a GGA functional, on ilmenite-type $\mathrm{ZnTiO}_{3}$ [25], and yields a bandgap of $3.1 \mathrm{eV}$ (which will be an underestimation as happens always when using this theory level). On the other hand, no reports exist using DFT on N-dped Zn titanates. This contrasts with the very extense literature on theoretical studies of the electronic structure of both $\mathrm{TiO}_{2}$ and $\mathrm{ZnO}$ that has been developed during several decades. For the former, besides earlier tight-binding studies of rutile-type $\mathrm{TiO}_{2}$ in the seventies [26] more advanced calculations calculations were started in the nineties for rutile using LDA [27] and for anatase using Hartree-Fock theory [28]; for $\mathrm{ZnO}$ empirical pseudopotential-based calculations go back as far as 1973 [29]. Concerning N-doped photocatalysts for use in the visible light range, which will be addressed also here, a number of calculations exist for $\mathrm{TiO}_{2}$; restricting ourselves to the charge-balanced case (i.e. without unpaired electrons), which has been evidenced by theoretical studies [30] to be the most realistic one for the best characterized preparations which use $\mathrm{NH}_{3}$ as source of nitrogen, extensive work besides the said ref. 30 has been carried out among others by Pacchioni et al. [31]. For N-doped $\mathrm{ZnO}$ less theoretical work has been done (mostly dealing with uncompensated doping); it has been focused mainly on the possibilities of the doped material in spintronics or electronic devices [32], but photocatalysis-oriented studies also exist [33]. Among N-containing mixed oxides involving $\mathrm{Ti}$ or $\mathrm{Zn}$ (but not both together) the calculations by Domen's group on $(\mathrm{Zn}, \mathrm{Ge}),(\mathrm{Zn}, \mathrm{Ga})$ and $(\mathrm{La}, \mathrm{Ti})$ oxynitrides active in visible light-sensitive photocatalysis [34] can be mentioned.

All these calculations, when using a DFT-type approach, do it either at the LDA or GGA level or with one of the standard hybrid DFT functionals which use a fixed degree of Hartree-Foch exchange $(\alpha=0.25$ in the PBE0 or HSE functionals, the value being based on theoretical considerations, although HSE introduces an additional screening effect; and $\alpha=0.20$ in the B3LYP functional, the value being obtained by fitting to experimental thermochemical data). As will be shown here, the value $\alpha=0.25$ is close to 
the best-suited one for $\mathrm{ZnO}$, so it is not surprising that relatively good results can be found for the bandgap of this oxide with the PBE0 functional, while for anatase the optimum $\alpha$ value is significantly lower than any of the two standard ones mentioned above. The present work handles consistently for the first time with one same fully first principles treatment the bandgaps of such a family of different single and mixed oxide photocatalysts, reaching good concordance with experiment at least for the end members of the family.

\section{Calculation methods}

DFT calculations at the GGA level (functional PBE) were made using program VASP [35], which expands the wavefunctions and electronic densities in plane waves, and representing with the PAW method [36] the inner electronic cores, which included 18, 12, 2 and 2 electrons for $\mathrm{Zn}, \mathrm{Ti}, \mathrm{N}$ and $\mathrm{O}$ respectively. The DFT+U approach, with $\mathrm{U}=7.0 \mathrm{eV}$, was used to handle the $3 \mathrm{~d}$ electrons of $\mathrm{Zn}$, in order to achieve a correct location of these levels and consequently a good estimation of the mixing between these orbitals and the oxygen orbitals which make most of the valence band. The plane wave energy cutoff was $400 \mathrm{eV}$, and the Brillouin zones corresponding to the primitive cells were sampled with gamma-centred Monkhorst-Pack meshes having between 8x8x8 and $11 \times 11 \times 11$ points (depending on cell size). This approach was used for initial geometry relaxations prior to hybrid functional calculations and also for total energy evaluations (these latter using an energy cutoff of $500 \mathrm{eV}$ to get more accurate results).

Final structural relaxations and determination of the main electronic structure features of the so relaxed lattices were carried out using hybrid functionals, which are able to compensate largely the known inadequacy of pure DFT at the LDA or GGA levels for computing band gaps. For several of the structures studied here doing this with a plane wave based code as VASP would be computationally very demanding due to the large number of atoms in them. Because of this, program CRYSTAL09 [37] was used here for all hybrid functional calculations. This program expands wavefunctions and densities in combinations of atom-centred functions of gaussian shape. The basis set used for oxygen was the 8-411d11G basis set reported by Valenzano et al. [38]; for nitrogen the 6-31d1G basis set of Gatti et al. [39] was used and for titanium the 86411(d31)G basis set made by Corá [40] was used, augmented as recommended by Di Valentin et al. [31b] with an additional d diffuse function for which an exponent 0.12 was adopted. For Zn the Stevens' relativistic equivalent core potential (RECP) keeping 20 electrons in the valence space [41] was used, as well as the corresponding basis set given in the same work; however the most diffuse sp function in the latter basis set, which is optimized for molecular systems, had to be changed as it gave rise to linear dependencies and instabilities in the periodic calculations, its exponent being therefore increased from 0.0537 to 0.09 , which value proved to minimize the total electronic energy in calculations on $\mathrm{ZnO}$. In the CRYSTAL09 calculations the Brillouin zone sampling used was the same as with VASP. The hybrid functional used was of PBE0 type [42], but with the fraction $\alpha$ of Hartree-Fock exchange modified according to the criteria explained further below.

In this work a complication arose because, as explained in the Results section, the known inadequacy of DFT-GGA methods to reproduce experimental bandgap values cannot be corrected with one same hybrid functional simultaneously for $\mathrm{TiO}_{2}$ and $\mathrm{ZnO}$, i.e. if the same functional is used for both oxides the bandgaps found for them are correct only if the fraction $\alpha$ of $\mathrm{HF}$ exchange used is higher for $\mathrm{ZnO}$ than for $\mathrm{TiO}_{2}$. That it may be reasonable to use different $\alpha$ values for different materials can be justified if 
one considers that, as discussed recently by Alkauskas et al. [43] and Marques et al. [44], the use of a fraction ( $\alpha$ ) of HF exchange reflects the fact that the HF exchange is subjected to screening, and that this latter is related to the dielectric properties of the material considered. These works indicate that it is quite reasonable to assume $\alpha=1 / \varepsilon_{\infty}$, where $\varepsilon_{\infty}$ is the high frequency dielectric constant; the latter authors show in fact that using $\alpha$ values chosen in this way allows obtaining with rather good approximation the bandgap $\mathrm{E}_{\mathrm{g}}$ for a series of different semiconductors. As will be shown below, using for both $\mathrm{ZnO}$ and anatase $\alpha$ values computed according to this recipe from experimentally obtained $\varepsilon_{\infty}$ values allows to reproduce rather well their experimental bandgaps.

However, there are very few experimental data in the literature about the value of $\varepsilon_{\infty}$ for the $\mathrm{Zn}$-Ti compounds addressed here. To this author's knowledge there is one determination for a more or less well-defined $\mathrm{Zn}_{2} \mathrm{TiO}_{4}$ material [45] based on optical properties in the IR range, which gives $\varepsilon_{\infty}=2.9$ (implying $\alpha=0.345$, a rather high and therefore unlikely value); it must be noted that this result was obtained with samples having less than theoretical density. Other published measurements [14a] involve thin films of ill-defined composition and structure. It can be mentioned, on the other hand, that on the basis of the refractive index measured for a $\mathrm{Zn}_{2} \mathrm{TiO}_{4}$ single crystal [18] a value $\varepsilon_{\infty}=4.41$ (implying $\alpha=0.227$ ) can be derived; this seems more acceptable. Since no data other than these could be found, in order to proceed in a systematic and homogeneous way $\varepsilon_{\infty}$ will be computed here for all the materials studied in this work using the Coupled Perturbed Hartree-Fock/Kohn-Sham (CPHF/KS) method implemented in CRYSTAL09 according to the methodology of Ferrero et al. [46]. As will be shown below, quite reasonable values can be obtained for both $\mathrm{ZnO}$ and anatase with this method, giving confidence on its suitability for the present study.

\section{Results and discussion}

\subsection{Computing the bandgaps of the single oxide phases}

As said above, one same functional is unable to reproduce the bandgaps of both anatase and $\mathrm{ZnO}$. For example, mixing into the PBE functional a fraction $\alpha=0.20$ of $\mathrm{HF}$ exchange (the same used in the well known B3LYP functional) yields with the CRYSTAL09 code, once the structures are fully relaxed in both cell dimensions and atomic coordinates, bandgaps of $3.78 \mathrm{eV}$ (indirect) and $2.80 \mathrm{eV}$ (direct) for anatase and $\mathrm{ZnO}$ respectively. In both cases increasing $\alpha$ increases $\mathrm{E}_{\mathrm{g}}$ and viceversa; one same $\alpha$ value cannot therefore give the correct $E_{g}$ for both oxides. Thus the relationship $\alpha=1 / \varepsilon_{\infty}$ mentioned above was used to derive $\alpha$ from $\varepsilon_{\infty}$ values obtained experimentally either from optical properties in the IR range or, using the relationship $\varepsilon=n^{2}$, from the refractive index at photon frequencies below the onset of bandgap absorption. For anatase an isotropically averaged value $\varepsilon_{\infty}=5.68$ has been evaluated from IR properties [47] while a value $\varepsilon_{\infty}=6.44$ can be derived from the refractive index, resulting in $\alpha=0.176$ or 0.155 respectively; for $\mathrm{ZnO} \varepsilon_{\infty}$ values of 3.73 and 3.98 have been deduced from IR properties [48] (giving $\alpha=0.268$ and 0.251 respectively), while the refractive index gives $\varepsilon_{\infty}=4.0$, i.e. $\alpha=2.5$. Here $\alpha=0.165$ and 0.26 will be assumed to be acceptable experiment-based values for anatase and $\mathrm{ZnO}$ respectively.

The bandgaps computed with CRYSTAL09 for both oxides using these $\alpha$ values are $3.49 \mathrm{eV}$ (indirect) for anatase and $3.35 \mathrm{eV}$ (direct) for $\mathrm{ZnO}$; these are much closer to the experimental values (at $0 \mathrm{~K}$ ) mentioned above. The corresponding electronic structures, 
represented by the density of states curves so obtained, are presented in Fig. 2. These show, as expected, that the upper edges of the valence bands contain relatively small contributions from the metals, i.e. are constituted mainly by O-centred orbitals, while the bottom edges of the conduction bands are constituted mainly by metal-centred orbitals; a more detailed analysis (not shown) evidences that $3 \mathrm{~d}$ and $4 \mathrm{sp}$ orbitals are the main contributors to these latter edges in the $\mathrm{Ti}$ and $\mathrm{Zn}$ cases respectively, the much lower DOS values in the $\mathrm{ZnO}$ case being due mainly to the rather broader and more delocalized character of its $4 \mathrm{sp}$ band. Note also that the narrow, occupied $\mathrm{Zn} 3 \mathrm{~d}$ band appears well at the bottom of the valence band.

Thus there is a sound basis to assume that, at least for this class of semiconductors, it is appropriate to use a mixing coefficient $\alpha$ which is not the same for all systems but is tuned to the dielectric screening properties of each material. Since the $\varepsilon_{\infty}$ value is not known with certainty for most of the systems studied here, in the present work it will be computed with the CPHF/KS method mentioned above. To check the suitability of the method $\varepsilon_{\infty}$ was obtained in this way for both anatase and $\mathrm{ZnO}$, using as well the hybrid functional. The calculations showed that the obtained $\varepsilon_{\infty}$ (computed as the average of the three principal values of the corresponding dielectric tensor, obtained always for a fully relaxed structure) has in turn a moderate dependence on the $\alpha$ coefficient used in the calculation; therefore $\varepsilon_{\infty}$ was computed for different $\alpha$ values (with full geometry relaxation in all cases) and the resulting $1 / \varepsilon_{\infty}$ value was plotted against $\alpha$ to determine the intersection of the $1 / \varepsilon_{\infty}=\alpha$ line with the obtained curve, which turns out to be markedly linear as shown in Fig. 3a. One obtains thus, in a self-consistent and fully non empirical way, $\alpha=0.187$ for anatase and 0.292 for $\mathrm{ZnO}$.

The dependence of $E_{g}$ on $\alpha$ can be examined also. It is shown in Fig. 3b, where it can be seen that the band gaps resulting from the above mentioned theoretically derived $\alpha$ coefficients are 3.67 and $3.70 \mathrm{eV}$ for anatase and $\mathrm{ZnO}$ respectively; the DOS curves resulting from these calculations (not shown) are otherwise rather similar to those in Fig. 2. Thus a relatively good agreement is found between this first principles determination of $\mathrm{E}_{\mathrm{g}}$ and experiment; most importantly, the deviation (an overestimation by ca. $0.2 \mathrm{eV}$ ) is, besides small, nearly the same in both oxides. It seems reasonable to assume that the same method will give as well a rather good prediction of the $\mathrm{E}_{\mathrm{g}}$ value (even if it may be a bit overestimated) for the Zn,Ti compounds studied here.

\section{$\underline{3.2 \text { Electronic structures of } \mathrm{Zn} \text { titanates }}$}

Using the same method exemplified by Fig. $3 \alpha$ values were computed self-consistently for all three titanate structures depicted in Fig. 1, and with these values the corresponding electronic structures were obtained. For ilmenite-type $\mathrm{ZnTiO}_{3} \alpha=0.215$ was found, i.e. a value intermediate between those of $\mathrm{ZnO}$ and anatase. The computed bandgap value is however significantly larger than that obtained for both binary oxides: $E_{\mathrm{g}}=5.3 \mathrm{eV}$ (which would probably translate into an experimental value $\mathrm{E}_{\mathrm{g}}=4.5-5.0 \mathrm{eV}$ at ambient temperature, considering the above mentioned overestimation of this method and the thermal effects). The corresponding DOS curves are presented in Fig 4. One can see that the bottom of the conduction band is constituted mainly by Ti $3 \mathrm{~d}$ orbitals, which form a band split in two parts (due to $t_{2 g}$ and $e_{\mathrm{g}}$-type components, according to a more detailed analysis not shown here). These parts are narrower than in anatase, due probably to the lower overall overlap between these orbitals resulting from the smaller overall density of Ti atoms; this smaller width of the conduction band is thus probably the main reason for such wider gap. The $\mathrm{Zn} 4 \mathrm{sp}$ contributions seem to lie at higher 
energy; they mix to some extent with the $e_{g}$ branch of the Ti conduction band, but less with the $t_{2 g}$ branch, due perhaps to the nonbonding character of the latter. Ti and $\mathrm{Zn}$ seem thus to mutually dilute one another leading to a higher bandgap width. As shown by the band structure diagram, also shown in Fig. 4, the gap is indirect, but the minimum direct gap is quite close to it.

For the inverse spinel structure of $\mathrm{Zn}_{2} \mathrm{TiO}_{4}$ depicted in Fig, $1 \mathrm{~b}$ a mixing coefficient $\alpha=0.24$ is obtained by the mentioned method, and the density of states plot and band diagram obtained are presented as well in Fig. 4. The computed gap is again large, although this time somewhat lower $\left(\mathrm{E}_{\mathrm{g}}=5.0 \mathrm{eV}\right)$, and direct at the $\Gamma$ point; note the relatively good agreement in both $\mathrm{E}_{\mathrm{g}}$ and $\alpha$ value with the above mentioned experimental data obtained in a single crystal [18], which gives confidence to the method used here for $a b$ initio prediction of band gaps in this type of materials. The conduction band (made again mainly by $\mathrm{Ti}$ orbitals) is still separated in $t_{2 \mathrm{~g}}$ and $\mathrm{e}_{\mathrm{g}}$ components, but these are a bit broader than in the ilmenite-type $\mathrm{ZnTiO}_{3}$. The $4 \mathrm{sp}$ orbitals of the $\mathrm{Zn}$ atoms, especially of those located at tetrahedral sites, mix somewhat more with those of $\mathrm{Ti}$, which may contribute as well to broadening the conduction band.

Finally, for the spinel-type $\mathrm{Zn}_{2} \mathrm{Ti}_{3} \mathrm{O}_{8}$ structure in Fig. 1c the predicted $\alpha$ value is 0.235 ; the DOS and band diagram curves obtained for it are shown in Fig. 4. The computed gap (direct at the $\Gamma$ point) is again large: $\mathrm{E}_{\mathrm{g}}=5.13 \mathrm{eV}$; the features of the DOS (narrow conduction band split in $\mathrm{t}_{2 \mathrm{~g}}$ and $\mathrm{e}_{\mathrm{g}}$ manifolds in the case of $\mathrm{Ti}$, with $\mathrm{Zn} 4 \mathrm{sp}$ components mixing mainly with the $e_{\mathrm{g}}$ part) are similar to the other spinel structure. In this case the presence of vacancies in $25 \%$ of the octahedral sites may contribute also to narrowing the conduction band. In all the titanates it is shown, finally, that the filled $\mathrm{Zn} 3 \mathrm{~d}$ levels lie as expected at rather low energies, close to the bottom of the conduction band.

All these calculations, corresponding to well ordered structures, predict that these titanates would have rather wide bandgaps, probably around $4.5 \mathrm{eV}$ or even higher. But for the spinels the regular order of the Ti cations in the octahedral sites, shown in Figs. $1 \mathrm{~b}$ and $1 \mathrm{c}$, is almost surely absent in the real spinel-type materials used as photocatalysts, which always display XRD patterns indexable as cubic structures, i.e. without the decreased symmetry corresponding to the said orderings. It is thus convenient to check if changing this ordering affects to the electronic structures. For this purpose additional calculations were made for the simplest structures, i.e. those in which the primitive cell is that of the standard spinel, locating in their four octahedral sites either two $\mathrm{Ti}$ and two $\mathrm{Zn}$ ions (in the $\mathrm{Zn}_{2} \mathrm{TiO}_{4}$ case) or three $\mathrm{Ti}$ ions and one cation vacancy (in the $\mathrm{ZnTi}_{3} \mathrm{O}_{8}$ case); this gives structures having respectively Imma and $R-3 m$ space group symmetries. For these two structures (which according to total energy calculations have energies higher than the most stable ones by +0.23 and $+1.19 \mathrm{eV}$ per formula unit, respectively) the computed $\alpha$ values were 0.24 and 0.215 , and $\mathrm{E}_{\mathrm{g}}$ values were 4.00 and $3.99 \mathrm{eV}$ respectively; the corresponding DOS curves are shown in Fig. 5.

These results show clearly that, even though the $\alpha$ coefficients do not change much, the bandgap widths decrease substantially when altering the order in these structures, approaching (although maybe not reaching) the values of the single oxides. This is probably related to the lower local symmetries appearing around the ions, which lead to broadening of the conduction bands and, especially, of the valence bands, as is visible in the DOS plots of Fig. 5 when compared with those given for these same compositions in Fig. 4. An exhaustive analysis of the most likely value of the bandgaps in the fully disordered structures is out of the possibilities of this work, as it would require testing at the hybrid DFT level a relatively large number of superstructures, some of them with primitive cells having more than 100 atoms. Still, the results shown make clear that, 
although the gap values are likely to be in general higher than those of $\mathrm{ZnO}$ or anatase, their values may depend significantly on the materials synthesis conditions, as these will determine how the cations will locate and order relatively to one another during the crystallization process. This explains also the rather different bandgaps values found in the literature for these titanates when made in powder or polycrystalline thin film form.

\subsection{Nitrogen doping of the $\mathrm{Zn}$ titanates}

As mentioned in the introduction, several groups have reported the preparation of zinc titanates having nitrogen inserted in them (this being achieved mainly through high temperature treatments under $\mathrm{NH}_{3}$, which as said above should lead to a chargecompensated structure, at least in the case of $\mathrm{TiO}_{2}$, as shown in ref. 30) and displaying significant photocatalytic activity in the visible region [15]. $\mathrm{N}$-doping of $\mathrm{TiO}_{2}$ has been extensively studied in the literature as a method for obtaining visible light photocatalytic activity; when carried out through treatments of the solid with ammonia, the chemical process leading to a charge-compensated structure can be described with the reaction

$$
\mathrm{n} \mathrm{TiO}_{2}+2 \mathrm{NH}_{3} \rightarrow \mathrm{Ti}_{\mathrm{n}} \mathrm{O}_{2 \mathrm{n}-3} \mathrm{~N}_{2} \square^{\mathrm{A}}+3 \mathrm{H}_{2} \mathrm{O}
$$

where $\square^{\mathrm{A}}$ represents an anion vacancy which must appear to compensate the higher anionic formal charge of nitrogen (under these synthesis conditions hole doping can be excluded). This is an endothermic process; computing with DFT (at the GGA level, using the VASP code) the energetics of this process (in the low temperature limit) using for the $\mathrm{N}$-containing materials high symmetry structures one finds an energy change equal to +3.54 and $+2.57 \mathrm{eV} / \mathrm{N}$ atom for cases $\mathrm{n}=3$ and $\mathrm{n}=16$ respectively.

With zinc titanates, however, a new situation can arise: because their spinel forms must contain cation vacancies for any Ti: $\mathrm{Zn}$ ratio higher than 1:2, in these cases the compensation for the higher anionic charge of nitrogen can be achieved not only with anion vacancies, but also by decreasing the number of cation vacancies. Obviously this may happen to higher extent for the highest Ti:Zn ratios. One limiting case is given by the mixed oxide phase with Ti: $\mathrm{Zn}$ ratio $=3: 2$, which has the highest amount of cation vacancies; all of them may be annihilated through nitriding (accompanied by migration of part of the $\mathrm{Zn}$ ions to octahedral sites) in a process formally describable as

$$
6 \mathrm{Zn}^{[4]}{ }_{2}\left\{\mathrm{Ti}_{3} \square^{\mathrm{C}}\right\}^{[6]} \mathrm{O}_{8}+16 \mathrm{NH}_{3} \rightarrow 5 \mathrm{Zn}_{2}^{[4]}{ }_{2}\left\{\mathrm{Zn}_{2 / 5} \mathrm{Ti}_{18 / 5}\right\}{ }^{[6]} \mathrm{O}_{24 / 5} \mathrm{~N}_{16 / 5}+24 \mathrm{H}_{2} \mathrm{O}
$$

where the superscripts in brackets indicate tetrahedral or octahedral sites and $\square^{\mathrm{C}}$ refers to cation vacancies. The energy balance for this process, computed with VASP at the GGA level using a final structure with the highest symmetry and smallest primitive cell possible, amounts to $\Delta \mathrm{E}=+1.70 \mathrm{eV} / \mathrm{N}$ atom, i.e. is clearly lower than in the $\mathrm{TiO}_{2}$ case. Of course lower degrees of nitridation, and of cation vacancy suppression, are possible; for example, one could have a reaction such as

$$
9 \mathrm{Zn}^{[4]}{ }_{2}\left\{\mathrm{Ti}_{3} \square^{\mathrm{C}}\right\}^{[6]} \mathrm{O}_{8}+16 \mathrm{NH}_{3} \rightarrow 8 \mathrm{Zn}^{[4]}{ }_{2}\left\{\mathrm{Zn}_{1 / 4} \mathrm{Ti}_{27 / 8} \square^{\mathrm{C}}{ }_{3 / 8}\right\}^{[6]} \mathrm{O}_{6} \mathrm{~N}_{2}+24 \mathrm{H}_{2} \mathrm{O}
$$

in which only $2 / 3$ of the initial cation vacancies disappear. In this case the computed energy balance is $\Delta \mathrm{E}=+1.78 \mathrm{eV} / \mathrm{N}$ atom; i.e., comparing this result with that of reaction \{2\} shows that if the fraction of vacancies suppressed by each $\mathrm{N}$ atom is smaller the energy cost is higher. It is also possible to combine Eqs. 1 (with $n=3$ ) and 2 above to visualize a formal transfer of $\mathrm{N}$ atoms from anatase to the spinel structure, for one same 
$\mathrm{N}: \mathrm{O}$ ratio in the nitrided phase, accompanied by complete annihilation of cation and anion vacancies:

$$
3 / 4 \mathrm{Zn}_{2}^{[4]}{ }_{2}\left\{\mathrm{Ti}_{3} \square^{\mathrm{C}}\right\}^{[6]} \mathrm{O}_{8}+\mathrm{Ti}_{3} \mathrm{O}_{3} \mathrm{~N}_{2} \square^{\mathrm{A}} \rightarrow 5 / 8 \mathrm{Zn}^{[4]}{ }_{2}\left\{\mathrm{Zn}_{2 / 5} \mathrm{Ti}_{18 / 5}\right\}^{[6]} \mathrm{O}_{24 / 5} \mathrm{~N}_{16 / 5}+3 \mathrm{TiO}_{2}
$$

which has a net energy balance of $\Delta \mathrm{E}=-1.84 \mathrm{eV}$ per $\mathrm{N}$ atom. It is clear thus that inserting $\mathrm{N}$ atoms in such spinel-type zinc titanates is energetically more favorable than in the case of $\mathrm{TiO}_{2}$. This is easily understood since the elimination of ion vacancies, contrarily to their creation, increases the compactness of the crystalline matter (and therefore the Madelung energy) as well as the average number of bonds per atom in it. Another consequence is that substituting $\mathrm{O}$ by $\mathrm{N}$ makes possible to achieve in the spinel lattice higher Ti:Zn ratios; within the spinel structure the highest of these is realized (if one keeps always $\mathrm{Ti}$ in octahedral coordination, which is preferred by this cation, and $\mathrm{Zn}$ in tetrahedral sites) with the stoichiometry $\mathrm{ZnTi}_{2} \mathrm{O}_{2} \mathrm{~N}_{2}$. Starting from the $\mathrm{Zn}_{2} \mathrm{Ti}_{3} \mathrm{O}_{8}$ this could result, for example, from a reaction such as

$$
\mathrm{Zn}^{[4]}{ }_{2}\left\{\mathrm{Ti}_{3} \square^{\mathrm{C}}\right\}^{[6]} \mathrm{O}_{8}+\mathrm{TiO}_{2}+4 \mathrm{NH}_{3} \rightarrow \mathrm{Zn}^{[4]}{ }_{2}\left\{\mathrm{Ti}_{4}\right\}^{[6]} \mathrm{O}_{4} \mathrm{~N}_{4}+6 \mathrm{H}_{2} \mathrm{O}
$$

for which the computed energy balance is $\Delta \mathrm{E}=+1.66 \mathrm{eV} / \mathrm{N}$ atom, i.e. very similar to that of reaction $\{2\}$.

Of course these nitrided structures are expected to have smaller bandgaps than the Nfree oxides. To exemplify this one can compute the electronic structure of a spinel having the mentioned $\mathrm{ZnTi}_{2} \mathrm{O}_{2} \mathrm{~N}_{2}$ stoichiometry, taking for this an ordered structure which still has a fcc lattice and the same number of atoms per primitive cell as in a standard spinel, but in which the crystal symmetry is decreased to space group $F-43 m$ in order to accommodate two types of anion. A calculation as explained above yields for this composition and structure a best exchange mixing coefficient $\alpha=0.16$ (lower than for the mixed oxides; not unexpected since the more polarizable nitride anion will exert a more important screening effect). Using this $\alpha$ value the hybrid DFT calculation yields a predicted gap $\mathrm{E}_{\mathrm{g}}=2.52 \mathrm{eV}$, which probably will translate into a real value $\mathrm{E}_{\mathrm{g}} \approx 2.2 \mathrm{eV}$ at ambient temperature considering the above mentioned tendency of the method to overestimation; the resulting DOS structure is shown in Fig. 6. Furthermore, disorder effects at the anion site (not studied here) might cause some additional bandgap narrowing, similarly to the effect decribed above for the spinel oxide systems. As in other oxynitride materials $[31,34]$ the top of the valence band is now formed mainly by nitrogen-centered states, i.e. the $\mathrm{N}$ atoms modify the electronic structure by inserting levels near the top of the oxygen-based valence band. For lower concentrations of nitrogen the effect is similar, although smaller; for example, for a $\mathrm{Zn}_{4} \mathrm{Ti}_{7} \mathrm{O}_{12} \mathrm{~N}_{4}$ stoichiometry (closer to that achieved in experimental works $(\mathrm{N}: \mathrm{O} \approx 1: 7)$ [15], modeled with a structure of $P 2 / m$ symmetry (which was found to be the most stable one within this cell contents), with $50 \%$ of the cation vacancies suppressed and thus halfway between the $\mathrm{ZnTi}_{2} \mathrm{O}_{2} \mathrm{~N}_{2}$ oxynitride discussed above and the $\mathrm{Zn}_{2} \mathrm{Ti}_{3} \mathrm{O}_{8}$ oxide, the optimum $\alpha$ is found to be 0.175 and the resulting computed bandgap is $\mathrm{E}_{\mathrm{g}}=2.76 \mathrm{eV}$, which may translate into an experimental ambient temperature value $\mathrm{E}_{\mathrm{g}} \approx 2.45 \mathrm{eV}$. The corresponding DOS curves are shown as well in Fig. 6, where the band of states with predominant $\mathrm{N}$ character found at the top of the valence band appears with lower width (which effect contributes to the bandgap increase) as could be expected due to the lower nitrogen concentration.

It is worth noting. that, as in the above discussed zinc titanates, the bottom of the conduction band is formed mainly by Ti-centered states, implying that the chemistry processes that can be started by the photogenerated electrons will probably be more 
similar to those observed in anatase than to those characteristic of $\mathrm{ZnO}$. The holes will be stabilized mainly at N-centered states (localized or not); but, since the spinel structure is more compact and has a higher density of cation-anion bonds, this system is likely to be more stable against oxidative photocorrosion than other $\mathrm{N}$-containing photocatalysts discussed in the recent literature, perhaps with the exception of the $\mathrm{LaTiO}_{2} \mathrm{~N}$ compound (and any other similar one of perovskite type structure) which has also been proposed in recent years for the same aim [49]. Thus nitrided $\mathrm{Zn}$-Ti spinels constitute a promising class of materials for their use in photocatalytic processes with visible light, aimed at either decontamination or solar energy conversion.

\section{Conclusions}

With an adequate use of hybrid DFT calculations it is possible to achieve reasonable evaluations of zinc titanate bandgaps. For structures having the cation orderings known to be stable in these compounds the bandgaps are found to be rather higher than those of anatase or $\mathrm{ZnO}$, which may be due to a dilution effect. It is shown also that in the resulting electronic structures the lower conduction band edge is constituted always by Ti-centered $3 \mathrm{~d}$ orbitals. However, different cation orderings at the local atomic level can give significantly lower bandgaps; this implies that the final gaps of this family of photocatalysts, which normally show cation disorder, may depend strongly on the preparation conditions. This explains also the fact that different groups have reported in the literature different bandgap values for these compounds.

On the other hand, one can expect that starting from electronic structures obtained with the methodology followed here the calculation of optical absorption spectra, as done e.g. for $\mathrm{N}$-doped $\mathrm{TiO}_{2}$ by Harb et al. [30], would probably give a relatively accurate result, which could be then compared with experiment. This would be the subject of a separate publication. More accurate results could be obtained of course with a more advanced treatment based on the Bethe-Salpeter equation, but due to the computational cost of the latter this is still unfeasible for unit cells containing several tens of atoms as is the case of some of the systems studied here. Of additional interest is, furthermore, that the use of an atom-centered basis set might allow to include deep levels in the electronic transition calculation, so that following a similar approach even XANES spectra could be simulated, improving the treatment over those used in earlier simulations of e.g. rutile [27, 50, 51] and anatase [50]; note however that in principle only the dipole-induced transitions would be addressed in such calculation, leaving out probably the quadrupole-induced pre-edge features that in the cited earlier calculations have been found to be significant for a proper reproduction of the pre-edge features at least in the case of rutile. On the other hand, if using the CRYSTAL code this would have to be limited to levels that can be modeled adequately within a nonrelativistic calculation, which is here probably the case for the Ti and $\mathrm{O} 1 \mathrm{~s}$ levels but not for the $\mathrm{Zn}$ 1s levels.

Of particular interest is the result of this work, obtained through total energy DFT calculations, that the insertion of nitrogen as substituting anion in zinc titanates having high Ti: $\mathrm{Zn}$ ratios is significantly more favorable than in anatase from an energetic point of view, due to a cation vacancy annihilation effect which stabilizes the structure. Since low bandgaps approaching the $2.0 \mathrm{eV}$ value can be obtained in this way these materials, which also have a $\mathrm{Ti} 3 \mathrm{~d}$ orbitals-dominated conduction band edge, are promising candidates for constituting robust visible light-active photocatalysts. 


\section{Acknowledgements}

Thanks are given to National Plan project MAT2009-14625 and COST action 540 for financing, and to CESGA and CSIC for access to parallel computers (Finis Terrae and Trueno).

\section{References}

[1] O. Carp, C.L. Huisman, A. Reller, Prog. Solid State Chem. 2004, 32, 33.

[2] A. Fujishima, X. Zhang, D.A. Tryk, Surf. Sci. Reports 63 (2008) 515.

[3] M.D. Hernández-Alonso, F. Fresno, S. Suárez, J.M. Coronado, Ener. Environ. Sci. 2 (2009) 1231.

[4] a) G. Marcí, V. Augugliaro, M.J. López-Muñoz, C. Martín, L. Palmisano, V. Rives, M. Schiavello, R.J.D. Tilley, A.M. Venezia, J. Phys. Chem. B 105 (2001) 1033; b) R. Liu, H. Ye, X. Xiong, H. Liu, Mater. Chem. Phys. 121 (2010) 432;

[5] a) Z. Zhang, Y. Yuan, Y. Fang, L. Liang, H. Ding, L. Jin, Talanta 73 (2007) 523; b) M.S. Hamdy, P. Nickels, I.H. Abd-Elmaksood, H. Zhou, E.H. El-Mossalamy, A.O. Alyoubi, S. Lynch, A. Nathan, G. Thornton, J. Photochem. Photobiol. A: Chemistry 228 (2012) 1; c) C. Shifu, Z. Wei, L. Wei, Z. Sujuan, Appl. Surf. Sci. 255 (2008) 2478.

[6] a) Y. Jiang, Y. Sun, H. Liu, F. Zhu, H. Yin, Dyes Pigm. 78 (2008) 77; b) S. Liao, H. Donggen, D. Yu, Y. Su, G. Yuan, J. Photochem. Photobiol. A 168 (2004) 7; c) T.A. Khalyavka, E.I. Kapinus, T.I. Viktorova, N.N. Tsyba, Theor. Exp. Chem. 45 (2009) 234; d) C. Karunakaran, R. Dhanalakshmi, P. Gomathisankar, G. Manikandan, J. Hazardous Mater. 176 (2010) 799.

[7] R. Bickley, T. González-Carreño, J. Lees, J. Solid State Chem. 92 (1991) 178

[8] a) Y. Liu, X. Sun, Q. Tai, H. Hu, B. Chen, N. Huang, B. Sebo, X.-Z. Zhao, J. Power Sources 196 (2011) 475; b) L. Lin, J.M. Lin, J.H. Wu, S.C. Hao, Z. Lan, Mat. Res. Innov. 14 (2010) 370.

[9] a) M. Wang, C. Huang, Y. Cao, Q. Yu, Z. Deng, Y. Liu, Z. Huang, J. Huang, Q. Huang, W. Guo, J. Liang, J. Phys. D: Appl. Phys. 42 (2009) 155104; b) S. Panigrahi, D. Basak, Nanoscale 3 (2011) 2336.

[10] J. C. Conesa, J. Phys. Chem. C, accepted (2012), doi: 10.1021/jp306160c

[11] a) S.A. Mayén-Hernández, G. Torres-Delgado, R. Castanedo-Perez, J.M. Marin, M. Gutierrez-Villarreal, O. Zelaya-Angel, Solar Energy Mater. Solar Cells 91 (2007) 1454; b) G. Krylova, A. Brioude, S. Ababou-Girard, J. Mrazeka, L. Spanhel, Phys. Chem. Chem. Phys. 12 (2010) 15101; c) R. Iordanova, A. Bachvarova-Nedelcheva1, Y. Dimitriev, T. Iliev, Bulg. Chem. Commun. 43 (2011) 378; d) A.A. Ismael, Appl. Catal. B 85 (2008) 33; e) S.A. Ruffolo, M.F. La Russa, M. Malagodi, C. Oliviero Rossi, A.M. Palermo, G.M. Crisci, Appl Phys A 100 (2010) 829;

[12] a) J.-Z. Kong, A.-D. Li, H.-F. Zhai, H. Li, Q.-Y. Yan, J. Ma, D. Wu, J. Hazard. Mater. 171 (2009) 918; b) J.S. Jang, P.H. Borse, J.S. Lee, K.T. Lim, O.-S. Jung, E.D. Jeong, J.S. Bae, M.S. Won, H.G. Kim, Bull. Korean Chem. Soc. 30 (2009) 3021.

[13] P.H. Borse, C.R. Cho, K.T. Lim, T.E. Hong, E.D. Jeong, J.H. Yoon, S.M. Yu, H.G. Kim, J. Ceram. Proc. Res. 13 (2012) 42 
[14] a) C. Ye, S.S. Pan, X.M. Teng, H.T. Fan, G.H. Li, Appl. Phys. A 90 (2008) 375; b) C. Ye, Y. Wang, Y. Ye, J. Zhang, G. H. Li, J. Appl. Phys. 106 (2009) 033520.

[15] a) F. Grasset, G. Starukh, L. Spanhel, S. Ababou-Girard, D.-S. Su, A. Klein, Adv. Mater. 17 (2005) 294; b) F. Grasset, L. Spanhel, S. Ababou-Girard, Superlatt. Microstruct. 38 (2005) 300; c) D. Berthebaud, F. Grasset, V. Allegret-Maret, S. Ababou-Girard, S. Pechev, J. Phys. Chem. C 111 (2007) 7883; d) T. Hisatomi, K. Hasegawa, K. Teramura, T. Takata, M. Hara, K. Domen, Chem. Lett. 36 (2007) 558; e) T. Hisatomi, K. Teramura, J. Kubota, K. Domen, Bull. Chem. Soc. Jpn. 81 (2008) 1647.

[16] S.F. Bartram, A. Slepetys, J. Amer. Ceram. Soc. 44 (1961) 493.

[17] Y. Billiet, P. Poix, Bull. Soc. Chim. Fr. (1967) 215.

[18] L. Li, Y. Fan, D. Wang, G. Feng, D. Xu, Cryst. Res. Technol. 46 (2011) 475.

[19] U. Steinike, B. Wallis, Crys. Res. Technol. 32 (1997) 187.

[20] T. Aubert, F. Grasset, M. Potel, V. Nazabal, T. Cardinal, S. Pechev, N. Saito, N.

Ohashi, H. Haneda, Sci. Technol. Adv. Mater. 11 (2010) 044401

[21] C.L. Wang, W.S. Hwang, K.-M. Chang, H.H. Ko, C.-S. Hsi, H.H. Huang, M.C. Wang, Intl. J. Molec. Sci. 12 (2011) 935.

[22] H.T. Kim, S. Nahm, J.D. Byun, Y. Kim, J. Amer. Ceram. Soc. 82 (1999) 3476

[23] S. Cheah, D.L. Carpenter, K.A. Magrini-Bair, Energy Fuels 23 (2009) 5291.

[24] R. B. Rankin, A. Campos, H. Tian, R. Siriwardane, A. Roy, J.J. Spivey, D.S. Sholl, J. K. Johnson, J. Am. Ceram. Soc. 91 (2008) 584

[25] X.-C. Zhang C.-M. Fan, Z.-H. Liang, P.-D. Han, Acta Physico-Chimica Sinica 27 (2011) 47.

[26] a) N. Daude, C. Gout, L. Jouanin, Phys. Rev. B 15 (1977) 15 3229; b) K. Vos, J. Phys. C: Solid State Phys. 10 (1977) 3917.

[27] B. Poumellec, P. J. Durham, G. Y. Guo, J. Phys.: Condens. Matter 3 (1991) 819.

[28] A. Fahmi, C. Minot, B. Silvi, M. Causà, Phys. Rev. B 47 (1993) 11717.

[29] S. Bloom, I. Ortenburger, Phys. Status Solidi (b) 58 (1973) 561.

[30] M. Harb, P. Sautet, P. Raybaud, J. Phys. Chem. C 115 (2011) 19394.

[31] a) C. Di Valentin, E. Finazzi, G. Pacchioni, A. Selloni, S. Livraghi, M. C. Paganini, E. Giamello, Chem. Phys. 339 (2007) 44; b) C. Di Valentin, E. Finazzi, G. Pacchioni, A. Selloni, S. Livraghi, A. M. Czoska, M. C. Paganini, E. Giamello, Chem. Mater. 20 (2008) 3706; c) A. M. Czoska, S. Livraghi, M. C. Paganini, E. Giamello, C. Di Valentin, G. Pacchioni, Phys. Chem. Chem. Phys. 13 (2011) 136.

[32] a) M. Guo, X. D. Zhang, Modern Phys. Lett. B 23 (2009) 3243; b) J. L. Lyons,_A. Janotti, C. G. Van de Walle, Appl. Phys. Lett. 95 (2009) 252105; c) H. Xu, A. L. Rosa, T. Frauenheim, R. Q. Zhang, Phys. Status Sol. B 247(2010) 2195.

[33] see e.g. F. Gallino, C. Di Valentin, G. Pacchioni, M. Chiesa, E. Giamello, J. Mater. Chem. 20 (2010) 689.

[34] a) Y. Lee, H. Terashima, Y. Shimodaira, K. Teramura, M. Hara, H. Kobayashi, K. Domen,M. Yashima, J. Phys. Chem. C 111 (2007) 1042; b) M. Yashima, H. Yamada, K. Maeda, K. Domen, Chem. Commun. 46 (2010) 2379 .

[35] G. Kresse, J. Hafner, Phys. Rev. B 47 (1993) R558. 
[36] a) P. E. Blöchl, Phys. Rev. B 50 (1994) 17953; b) G. Kresse, J. Joubert, Phys. Rev. B 59 (1999) 1758.

[37] R. Dovesi, V. R. Saunders, C. Roetti, R. Orlando, C. M. Zicovich-Wilson, F. Pascale, B. Civalleri, K. Doll, N. M. Harrison, I. J. Bush, Ph. D’Arc, M. Llunell, CRYSTAL09 User's Manual, Università di Torino (Torino, 2010).

[38] L. Valenzano, F. J. Torres, K. Doll, F. Pascale, C. M. Zicovich-Wilson, R. Dovesi, Z. Phys. Chem. 220 (2006) 893.

[39] C. Gatti, V.R. Saunders, C. Roetti, J. Chem. Phys. 101 (1994) 10686.

[40] F. Corá, Mol. Phys. 103 (2005) 2483.

[41] W. J. Stevens, M. Krauss, H. Basch, P. G. Jasien, Can. J. Chem. 70 (1992) 612.

[42] C. Adamo, V. Barone, J. Chem. Phys. 110 (1999) 6158

[43] A. Alkauskas, P. Broqvist, A. Pasquarello, Phys. Status Solidi B 248 (2011) 775.

[44] M. A. L. Marques, J. Vidal, M. J. T. Oliveira, L. Reining, S. Botti, Phys. Rev. B 83 (2011) 035119.

[45] M. V. Nikolic, N. Obradovic, K.M. Paraskevopoulos, T.T. Zorba, S.M. Savic, M.M. Ristic, J Mater Sci 43 (2008) 5564.

[46] M. Ferrero, M. Rérat, R. Orlando, R. Dovesi, J. Chem. Phys. 128 (2008) 014100; ibid. J. Comput. Chem. 29 (2008) 1450.

[47] R. J. Gonzalez, R. Zallen, H. Berger, Phys. Rev. B 55 (1997) 7014.

[48] a) P. Ooi, S. Lee, S. Ng, Z. Hassan, H. Abu Hassan, J. Mater. Sci. Technol. 27 (2011) 465; b) E. F. Venger, A. V. Melnichuk, L. L. Melnichuk, Y. A. Pasechnik, Phys. Status Solidi (b) 188 (1995) 823.

[49] A. Kasahara, K. Nukumizu, G. Hitoki, T. Takata, J.N. Kondo, M. Hara, H.

Kobayashi, K. Domen, J. Phys. Chem. 106 (2002) 6750.

[50] Z. Y. Wu, G. Ouvrard, P. Gressier, C. R. Natoli, Phys. Rev. B 55 (1977) 10382.

[51] a) D. Cabaret, Y. Joly, H. Renevier, C. R. Natoli, J. Synchrotron Rad. 6 (1999) 258; b) J. Chaboy, N. Nakajima, Y. Tezuka, J. Phys.-Condens. Matter 19 (2007) 266206. 


\section{Captions of the Figures}

Figure 1 Structures of (ordered) zinc titanates: a) ilmenite-type $\mathrm{ZnTiO}_{3}$; b) $\mathrm{Zn}_{2} \mathrm{TiO}_{4}$ inverse spinel; c) $\mathrm{ZnTi}_{3} \mathrm{O}_{8}$ cation-defective spinel, in which octahedral cationic vacancies are represented by unconnected spheres. The superindices in brackets designate the cation coordination number.

Figure 2- Density of states curves (total and projected on the cations) computed for anatase and $\mathrm{ZnO}$ using respectively $\alpha=0.16$ and 0.267 in the hybrid functional. For $\mathrm{ZnO}$ the total DOS is plotted also magnified by a $\mathrm{x} 5$ factor to better appreciate the conduction band bottom edge.

Figure $31 / \varepsilon_{\infty}$ (upper plot) and $\mathrm{E}_{\mathrm{g}}$ (lower plot) values computed for $\mathrm{ZnO}$ and anatase using different $\mathrm{HF}$ exchange mixing fractions $\alpha$; the experimental $\mathrm{E}_{\mathrm{g}}$ values are marked as well.

Figure 4 Upper part: DOS curves (total and metal atom-projected), and lower part: band structure diagram obtained for ilmenite-type $\mathrm{ZnTiO}_{3}$ (left graphs) and spinel-type $\mathrm{Zn}_{2} \mathrm{TiO}_{4}$ (center) and $\mathrm{Zn}_{2} \mathrm{Ti}_{3} \mathrm{O}_{8}$ (right graph), using the structures shown in Fig. 1. For $\mathrm{ZnTiO}_{3}$ the band diagram shows also the smallest gap, of indirect type.

Figure 5 DOS curves obtained for $\mathrm{Zn}_{2} \mathrm{TiO}_{4}$ (upper plot) and $\mathrm{Zn}_{2} \mathrm{Ti}_{3} \mathrm{O}_{8}$ (lower plot) with the cations ordered in the same way in all primitive cells of the parent spinel.

Figure 6 Densities of states (total and projected in atomic spheres) computed for the oxynitride spinels $\mathrm{ZnTi}_{2} \mathrm{O}_{2} \mathrm{~N}_{2}$ and $\mathrm{Zn}_{4} \mathrm{Ti}_{7} \mathrm{O}_{12} \mathrm{~N}_{4}$ 
Figure 1
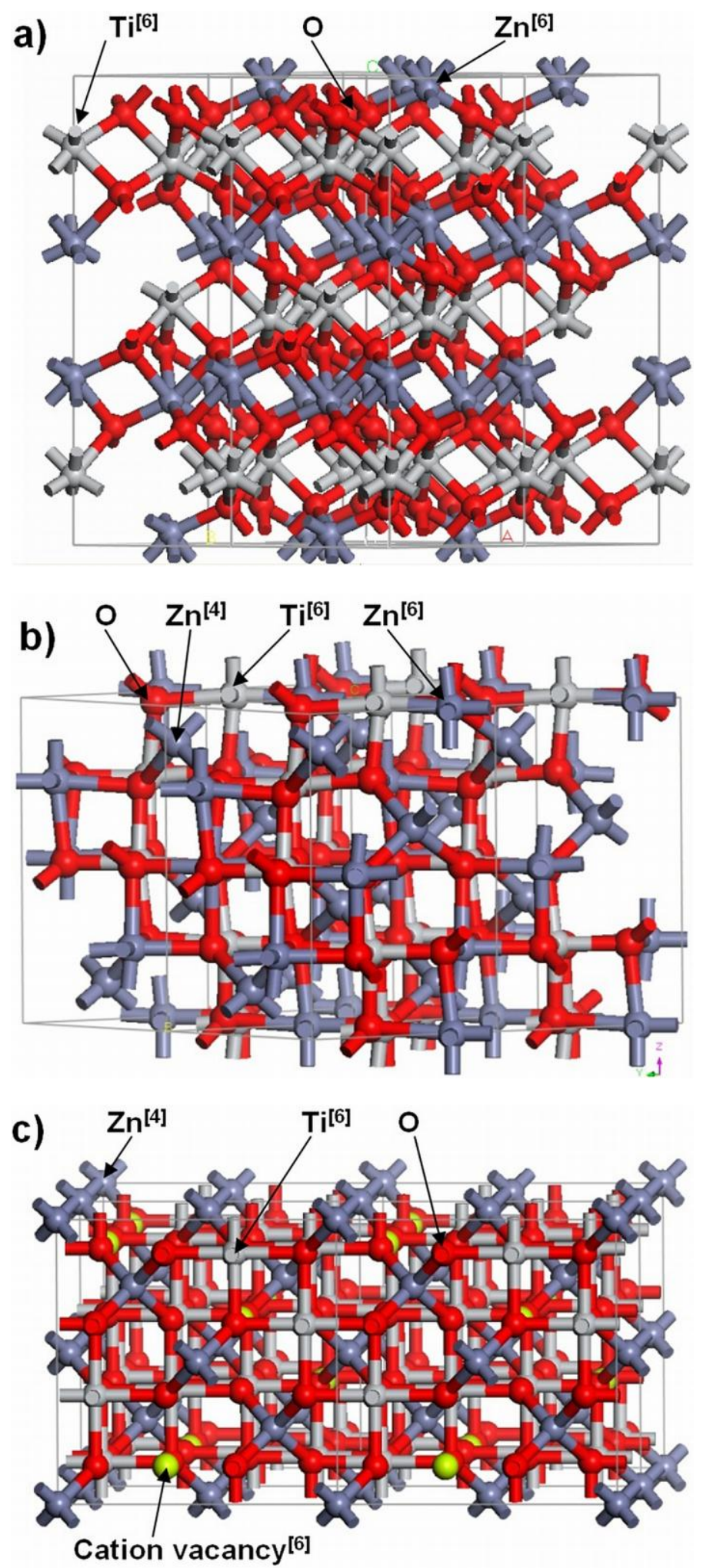
Figure 2

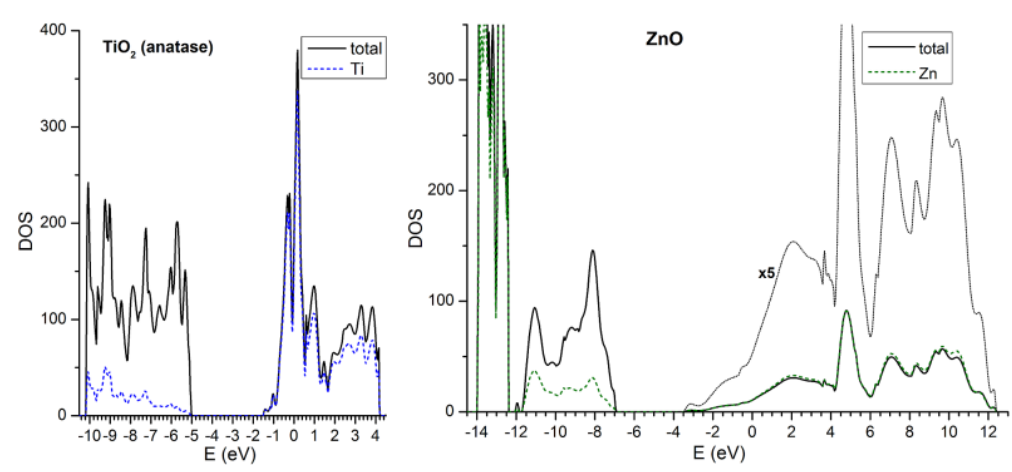


Figure 3

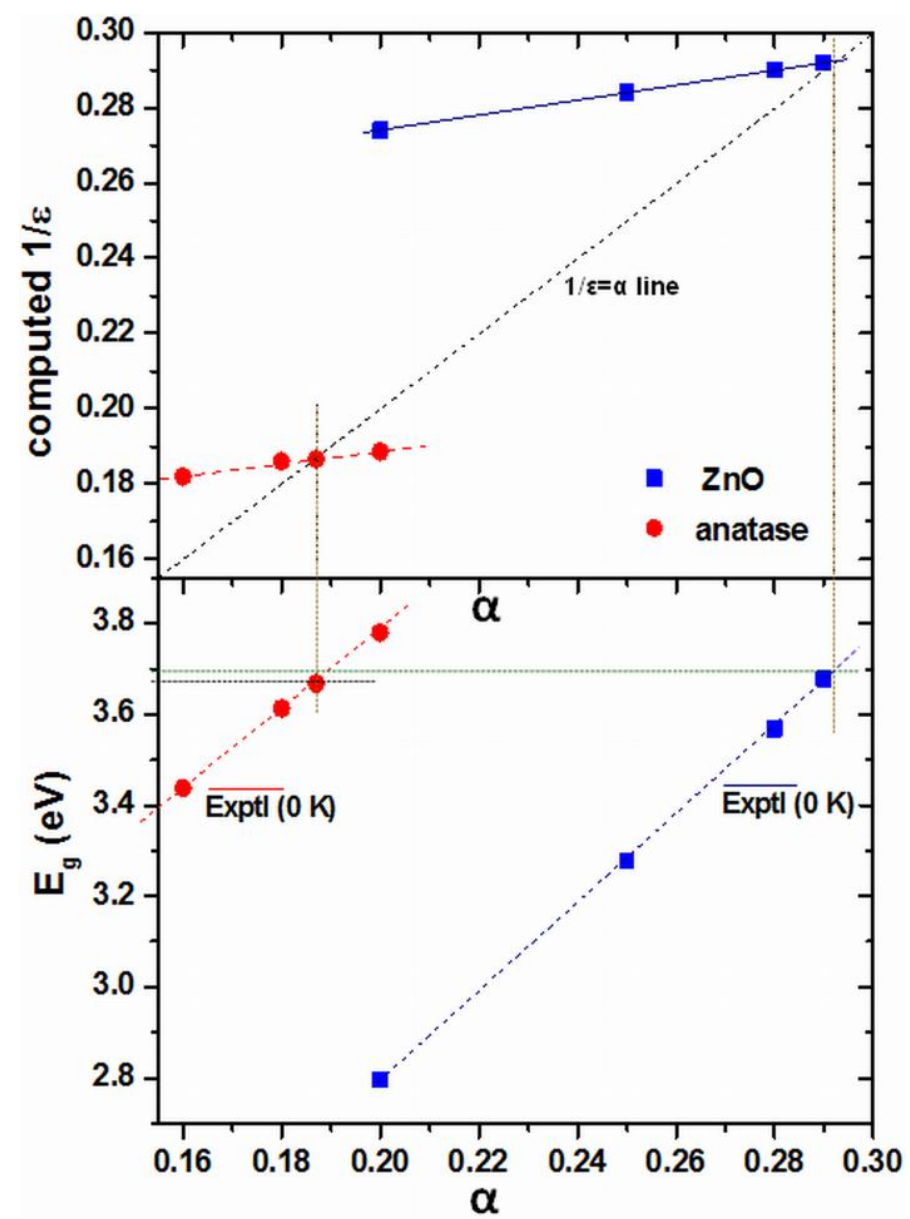




\section{Figure 4}
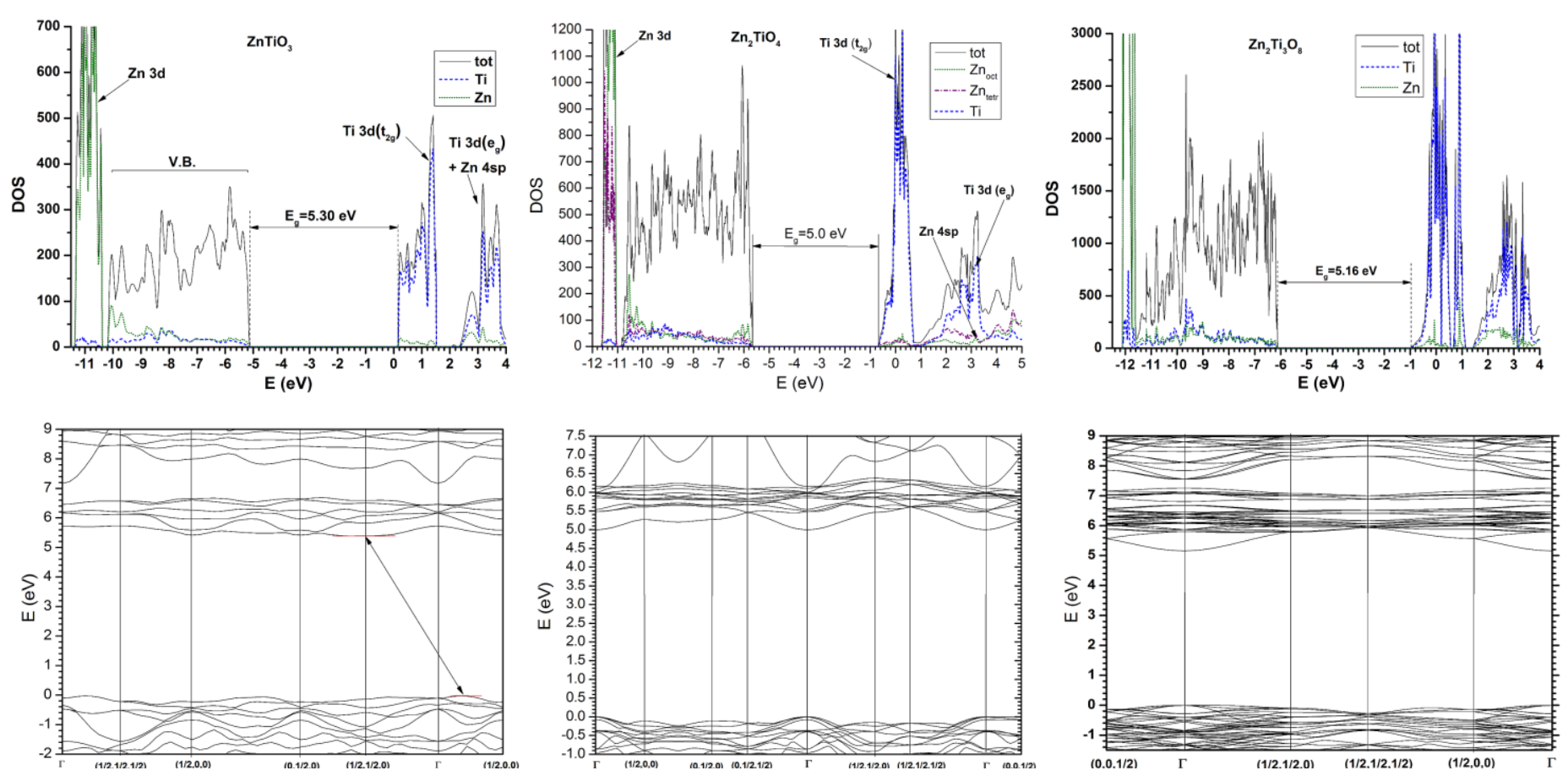


\section{Figure 5}
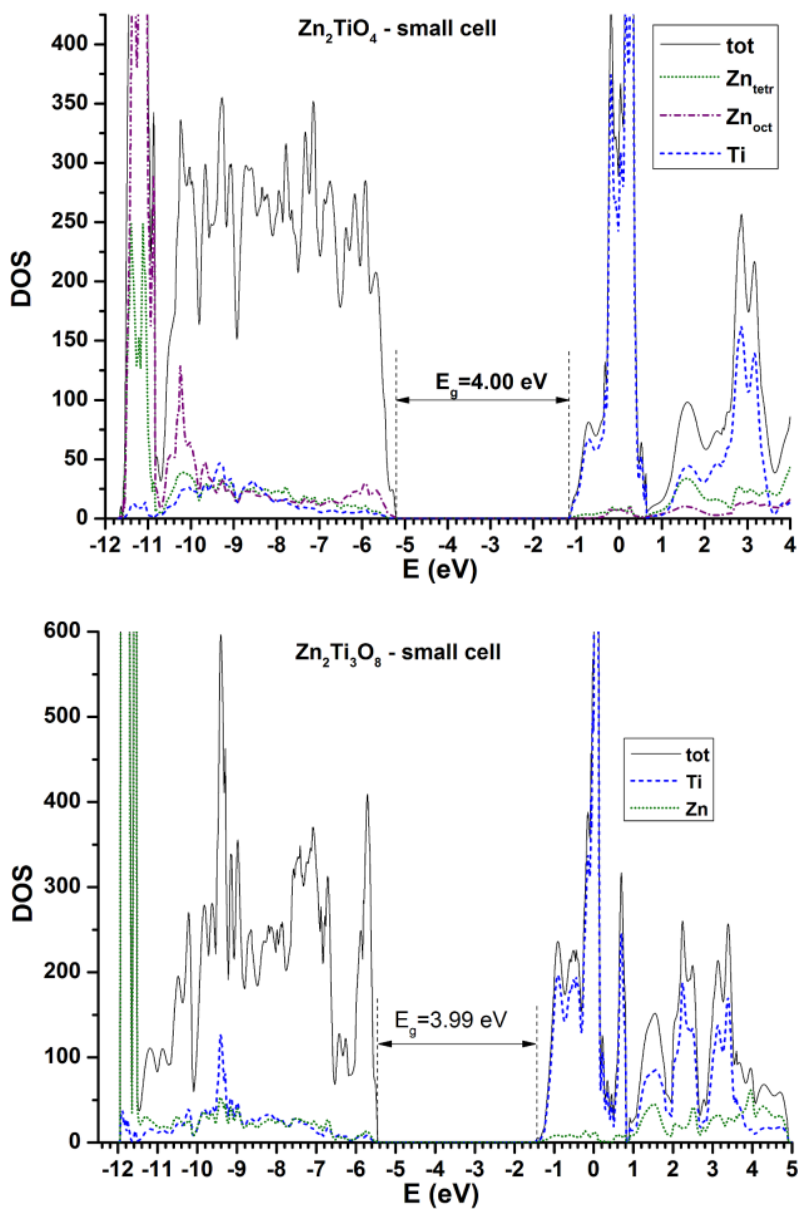


\section{Figure 6}
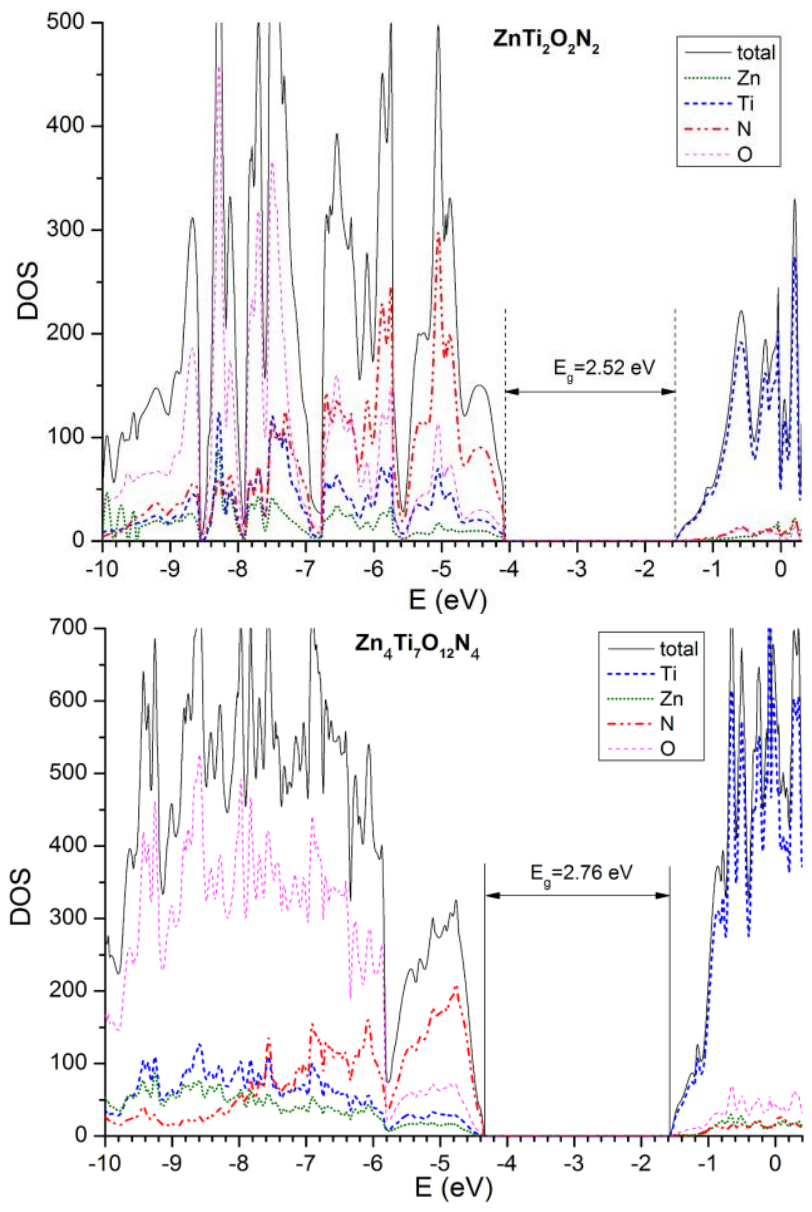


\section{Highlights}

Hybrid DFT with first principles-based exchange mixing gives reliable bandgaps Octahedral cation ordering affects strongly to the bandgaps of Zn-Ti spinels

Conduction band edge of zinc titanates is formed by Ti $3 \mathrm{~d}$ orbitals

$\mathrm{N}$-doping of $\mathrm{Zn}$ titanate, more favourable than in $\mathrm{TiO}_{2}$, can give bandgaps $<2.5 \mathrm{eV}$ 


\section{Graphical abstract}

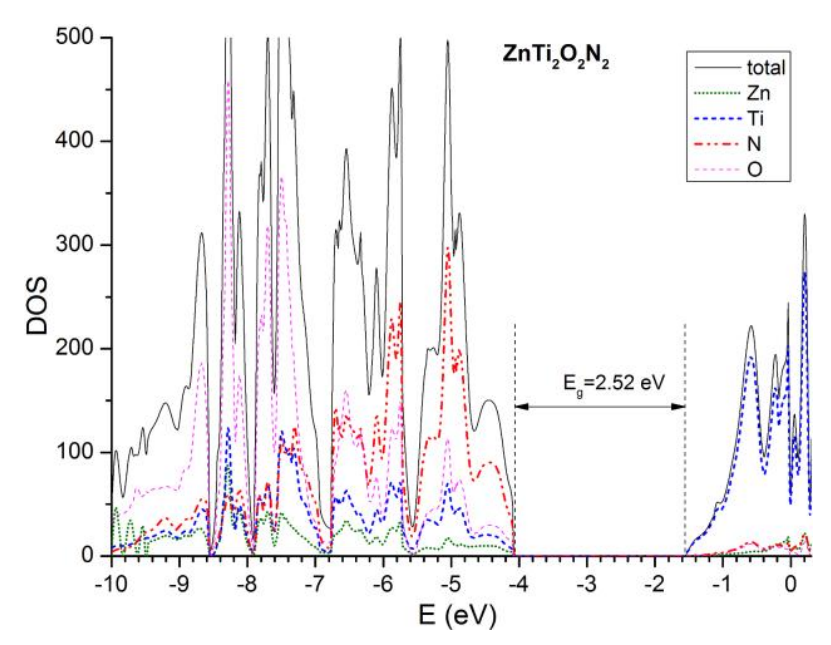

$3 / 4 \mathrm{Zn}^{[4]}{ }_{2}\left\{\mathrm{Ti}_{3} \square^{\text {Cation }}\right\}^{[6]} \mathrm{O}_{8}+\mathrm{Ti}_{3} \mathrm{O}_{3} \mathrm{~N}_{2} \square^{\text {Anion }} \rightarrow$

$5 / 8 \mathrm{Zn}^{[4]}{ }_{2}\left\{\mathrm{Zn}_{2 / 5} \mathrm{Ti}_{18 / 5}\right\}^{[6]} \mathrm{O}_{24 / 5} \mathrm{~N}_{16 / 5}+3 \mathrm{TiO}_{2}: \Delta \mathbf{E}=\mathbf{- 3 . 6 6} \mathbf{e V}$ 